\title{
Effects of secondary trimester maternal serum screening on the results of pregnancy
}

\author{
Kemal Dinc ${ }^{1}$ \\ Ramazan Ozyurt ${ }^{2}$ \\ Aytek S1k ${ }^{3}$ \\ Serkan Kumbasar ${ }^{4}$ \\ Yasam Kemal Akpak ${ }^{5}$ \\ Yilda Arzu Aba ${ }^{6}$
}

\begin{abstract}
In our study it was aimed to research the relations between pregnancy complications and frequencies of maternal and fetal complications which can be observed after the further follow-ups with biochemical indicators in gravid individuals whom found to be risky in quad test.120 patients who applied and had their labors conducted in İstanbul Training and Research Hospital and took quad test AFP (alpha fetoprotein), HCG (human chorionic gonadotropin), uE3 (unconjugated estriol), inhibin-A are included in our study. Conclusions planned to be obtained in this study are, IUGR (intrauterine growth deficiency), macrosomia, gestational diabetes, preeclampsia and preterm birth. $64(\% 53,4)$ out of 120 patients participated in the study had normal labors while $56(\% 46,6)$ of the patients had labors with caesarean birth. On 70 (\%58.3) patients whom did not develop obstetric complications, AFP value calculated as average as $1.00 \pm 0.74 \mathrm{MoM}$, uE3 value calculated as $0.89 \pm 0.4 \mathrm{MoM}, \mathrm{hCg}$ value calculated as $0.97 \pm 0.5 \mathrm{MoM}$ and inhibin A value calculated as an average of $0.95 \pm 0.5 \mathrm{MoM}$. On $50(\% 41.6)$ patients whom developed obstetric complications, AFP value found as average of $1,06 \pm 0,74$, uE3 value found as $0.96 \pm 0.39 \mathrm{MoM}$, hCG value found as $0.99 \pm 0.77$ $\mathrm{MoM}$ and Inhibin A value found as 1.023 $\pm 0.62 \mathrm{MoM}$. There were no significant deviation between the cases with obstetric complications and cases without obstetric complications in terms of AFP, uE3, HCG and Inhibin A values. There were no significant relation between threshold values of AFP, HCG, uE3 and inhibin A which are used in quad test as secondary trimester serum indicators in low risk populations and pregnancy complications.
\end{abstract}

Keywords: Serum scan test; alfa-fetoprotein; human chorionic gonadotropin; inhibin A; bad obstetric results.

\footnotetext{
${ }^{1}$ Op. Dr. Department of Obstetrics and Gynecology, Istanbul Research and Education Hospital, Istanbul, Turkey, dr.kemaldinc@hotmail.com

2 Op. Dr. Department of Obstetrics and Gynecology, Istanbul Research and Education Hospital, Istanbul, Turkey, ramazanozyurt24@gmail.com

3 Assistant Professor, Ph.D., Department of Obstetrics and Gynecology, Istanbul Aydın University, Istanbul, Turkey, bulataytek@hotmail.com

${ }^{4}$ Op. Dr. Department of Obstetrics and Gynecology, Sakarya Research and Education Hospital, Sakarya, Turkey, dr.skumbasar@gmail.com

5 Op. Dr. Department of Obstetrics and Gynecology, Dışkapı Yıldırım Beyazıt Training and Research Hospital, yasamaster@gmail.com

${ }^{6}$ Assistant Professor, Ph.D., Bandirma Onyedi Eylul University, Health Science Faculty, Faculty of Health Science, Nursing Department, Balıkesir, Turkey, yildaarzum@hotmail.com
} 
Dinc, K., Ozyurt, R., S1k, A., Kumbasar, S., Akpak, Y. K., \& Aba, Y. A. (2017). Effects of secondary trimester maternal serum screening on the results of pregnancy. Journal of Human Sciences, 14(4), 3653-3662. doi:10.14687/jhs.v14i4.4806

\section{Introduction}

During antenatal follow up, using biochemical screen tests besides ultrasonography for diagnosing fetal anomalies provided better pregnancy results. Besides assignation of risk for chromosomal and structural anomalies, biochemical indicators used in screen tests found to be used for forecasting pregnancy complications (Bobyr \& Vile, 2005; 152). In the early 1970s the only method for diagnosing Down syndrome in fetus was the age of the mother; all the women at the age of 35 or above were suggested to conduct amniocenteses. During 1980s secondary trimester mother serum biochemical indicators added to the age of the mother as a new screening method (James et al., 2008). At the start of the usage of triple test Down syndrome diagnosis rate obtained as \% 70. the 16th week of the pregnancy median values of AFP (alpha fetoprotein), uE3 (unconjugated estriol), hCG ( human chorionic gonadotropin) concentrations found to be different in the gravids carrying trisomy 21 fetus compared to normal fetus carrying mothers. Screen test called as "triple test" was suggested for by considering that these hormones might be used for screening the risky groups. Different indicators combined in order to increase the sensibility of the biochemical screen test. Addition of Inhibin-A to triple screen test is the most commonly used one. On the pregnancy with Down syndrome it was reported that though inhibit. An increases it cannot be used for calculating the trisomy 18 risk (Kafkasl1, 2004). On the gravids diagnosed with lower levels of PAPP-A (Pregnancy-Associated Plasma Protein),complications as intrauterine growth deficiency (IUGR), premature birth, preeclampsia and stillbirth are observed to be increasing compared to gravids which are not diagnosed with lower levels of PAPP-A (Smith et. al., 2002). On the gravids diagnosed with higher $\beta$-hCG levels, IUGR, preterm birth, preeclampsia and fetal loss rates observed to be increasing compared to gravids with normal $\beta$-hCG levels (Chandra et. al., 2003). Thus there are some studies reporting the relation between lower estriol levels and further preeclampsia, it is not a sensitive indicator (Lindheimer et. al., 2003). Human placenta, decidua and fetal membranes are the major areas for production of mother serum, amniotic fluid, inhibin-A and inhibin-B in cord blood. Inhibin-A found in mother's blood mainly synthesized by placenta (Wallace et. al., 1997). Neural tube deficiency (NTD) is the secondary commonly observed fetal congenital malformation following cardia anomalies (Knoshnood et. al., 2011). Alpha fetoprotein is used in NTD screening for over 30 years while ultrasonography (USG) is used for diagnosis. (Krantz et. al., 2010). As skin to be intact on $\% 10$ of the NTDs, while higher MSAFP values are not found in these cases, it is not efficient for NTD screening (Cameron \& Moran, 2009).

\section{Material and Methods}

In our study it was aimed to study the relations between complications of pregnancies and frequencies of maternal and fetal complications which can be observed after the further follow-ups with biochemical indicators in gravids whom found to be risky in quad test for Down syndrome.

120 patients which are applied to pregnancy policlinic of Istanbul Training and Research Hospital between 2 January 2012 and 2 July 2013 and conducted quad test (AFP, hCG, uE3) (AFP: Alfa-Fetoprotein, hCG: Human Chorionic Gonadotropin, uE3:unconjugated oestriol), inhibin-A ) and had their labors in our hospital were included in the study. Quad test results and obstetric complications of the patients participated in the study were compared. Study conducted in İstanbul Training and Research Hospital perinatology and delivery unit following the approval from Hospital Training and Planning Committee and Committee of Ethics. Within the indicated dates, patients considered within the scope of the study were informed and included in the study following their signed approval on the form of approval.

Criterias for inclusion in our study, are singleton gravids who took quad test between 16th and 20th week as per their last menstruation date, no presence of miscarriage risk (vaginal bleeding, pain etc.), no exposure to medication or radiation during the pregnancy within study 
Dinc, K., Ozyurt, R., S1k, A., Kumbasar, S., Akpak, Y. K., \& Aba, Y. A. (2017). Effects of secondary trimester maternal serum screening on the results of pregnancy. Journal of Human Sciences, 14(4), 3653-3662. doi:10.14687/jhs.v14i4.4806

period, no consanguineous marriage, no presence of blood incompatibility, no history of baby birth with fetal anomaly and be aged between 16 and 42. Exclusion criterias in our study are multiple pregnancy, no observation of fetal hearth beat between 16th and 20th weeks, fetal anomaly diagnosed in ultrasound, gravids who did not conduct labor in our hospital, individuals diagnosed with diabetes in presentational period, presence of bad obstetric history and gravids below 16 years of age and older than 42 years of age. In addition to the quad test markers of the 120 gravids within the criterias of the study; obstetric histories, physical examinations, fetal obstetric ultrasonography, amniotic fluid indexes, birth types, Aantenatal and postnatal pregnancy complications (preeclampsia, early membrane rupture, preterm birth, Small Gestational Age (SGA), gestational diabetes Mellitus (GDM)) biochemical results were searched from the patients' files. Labor types and fetal birth weight information were collected from birth registrations by retrospective inspections. Information of the patients were evaluated after the labor.

Findings planned to be obtained as a result of this study comprised of intrauterine growth deficiency (IUGR), macrosomia, gestational Diabetes (GDM), preeclampsia and preterm birth. Babies born below the 10th percentile as per the pregnancy week are accepted as small gestational age (SGA). Macrosomia as per the pregnancy age was used for defining the newborns which were born over 90th percentile of gestation week in terms of birth weight. Heavy preeclampsia, if no preeclampsia proteinuria were present, defined as the presence of symptoms and/or findings or $1+$ or more proteinuria and blood pressure over $140 / 90 \mathrm{mmHg}$. Birth before the 37 th pregnancy week defined as preterm birth. 2 of the 100 gram oral glucose tolerance test results to be higher as per ACOG criteria accepted as gestational diabetes. PPROM (Preterm premature rapture of membranes) described as the arrival of amnion fluid as a result of the spontaneous tearing of amnion membrane before 1 or more hours prior to start of the activity before 37 th pregnancy week.

\section{Statistical Analysis}

Descriptive and analytical statistical analysis were conducted for all the patients using SPSS 15.0 (Statistical Package for the Social Sciences Inc.; Chicago, IL, ABD) software. For continuous measured variables, descriptive statistics were presented as average \pm and standard deviation as presenting minimum and maximum values while quantitative variables were presented as number of cases and percentiles (\%). Presence of statistically significant deviation between groups in terms of normal distributed continuously measured variables were evaluated with $\mathrm{T}$ test while the importance of the deviance between the groups for non-normal distributed continuously measured variables were evaluated with Mann Whitney U test. Study groups evaluated in two groups as gravids with complications and gravids without complications during these analysis. In order to determine the more efficient factor in preeclampsia, preterm birth and IUGG, logistic regression analysis conducted. $\mathrm{p}<0.05$ accepted as statistically significant.

\section{Results}

Relations between pregnancy complications and secondary trimester screening results with HCG, AFP, uE3 and Inhibin a MoM values for 120 cases were evaluated. While IUGR were included in macrosomia, preterm birth, preeclampsia, gestational diabetes and gravids developed fetal distress complication group, gravids without problems in antenatal follow-up are comprised the group of patients without complications. 50 (41.6\%) of the patients experienced problems in antenatal follow-ups while $70(58.3 \%)$ of the patients did not develop complications. As we look on the demographical specifications of the cases included in the study, average age in the group without complications found as $29.46 \pm 5.87$ and average age in the complication group found as $27.74 \pm 5.92$. Average weight of the non-complications found as $65.52 \pm 10.32 \mathrm{~kg}$ and body mass index (BMI) were found as $25.08 \pm 4.14 \mathrm{~kg} / \mathrm{m}^{2}$ and average weight for the complications group found as $64.26 \pm 8.95 \mathrm{~kg}$ and BMI was found as $24.76 \pm 3.97 \mathrm{~kg} / \mathrm{m}^{2}$. Age of the mother, 
Dinc, K., Ozyurt, R., S1k, A., Kumbasar, S., Akpak, Y. K., \& Aba, Y. A. (2017). Effects of secondary trimester maternal serum screening on the results of pregnancy. Journal of Human Sciences, 14(4), 3653-3662. doi:10.14687/jhs.v14i4.4806

weight, height and BMI values for the complication group and non-complication groups are given in Table 1. There is no significant deviance between the cases in terms of age of mother, weight, height and BMI ( $\mathrm{p}>0.05)$.

Table 1. Age of Mother, weight, height and BMI values for the complication group and non-complication groups.

\begin{tabular}{lc|cc|c|c}
\hline & \multicolumn{2}{c|}{ Complication Unpresented } & \multicolumn{2}{c|}{ Complication Present } & \multirow{2}{*}{ p } \\
& $\mathbf{M}$ & $\mathbf{s d}$ & $\mathbf{M}$ & $\mathbf{s d}$ & \\
\hline Age (years) & 29.46 & 5.87 & 27.74 & 5.92 &, 115 \\
Weight & 65.52 & 10.32 & 64.26 & 8.95 &, 488 \\
Height & 161.85 & 6.10 & 161.40 & 6.52 &, 701 \\
BMI & 25.08 & 4.14 & 24.76 & 3.97 &, 680 \\
\hline
\end{tabular}

BMI: Body Mass Index, M: Mean, SD: standard deviation

$64(53.4 \%)$ out of 120 patients participated in the study had normal childbirths while 56 (46.6\%) of the patients had childbirths with caesarean birth. As the genders of the newborns considered for the 120 cases participated in the study, 59 (49.1\%) male babies and 61 (50.8\%) female babies were given birth. Distribution of the birth type and gender are given in table for complication and non-complication groups in Table 2. There is no significant deviation between the complication and non-complication group in terms of birth type and gender distribution $(\mathrm{p}>0.05)$.

Table 2. Distribution of birth type and gender between complication and noncomplication group.

$\begin{array}{cccc}\text { Complication Unpresented } & \text { Complication Present } & \mathrm{p} \\ \mathbf{n} & \% & \mathrm{n} & \%\end{array}$

\begin{tabular}{lccccc}
\hline Birth Type & & & & & \\
NSD & 40 & 57.1 & 24 & 48.0 & 0.332 \\
Caesarean & 30 & 42.9 & 26 & 52.0 & \\
Sex & & & & & \\
Male & 34 & 48.6 & 25 & 50.0 & 0.877 \\
Female & 36 & 51.4 & 25 & 50.0 & \\
\hline
\end{tabular}

NSD: Normal Spontaneous Birth

2 of the cases were observed with preeclampsia (4\%), 5 were observed with IUGR (10\%), 1 observed with early membrane rapture (EMR) (2\%), 20 observed with preterm activity $(40 \%), 7$ observed with fetal distress, 6 observed with GDM (12\%) and 9 observed with macrosomia $(18 \%)$ out of 120 gravids participated in the study (Table 3$)$. 
Dinc, K., Ozyurt, R., S1k, A., Kumbasar, S., Akpak, Y. K., \& Aba, Y. A. (2017). Effects of secondary trimester maternal serum screening on the results of pregnancy. Journal of Human Sciences, 14(4), 3653-3662. doi:10.14687/jhs.v14i4.4806

Table 3. Pregnancy Complication and Frequency

\begin{tabular}{lcc}
\hline \multicolumn{1}{c}{ Complication } & $\mathbf{n}$ & $\mathbf{\%}$ \\
\hline IUGR & 5 & 10.0 \\
Preeclampsia & 2 & 4.0 \\
EMR & 1 & 2.0 \\
Fetal Distress & 7 & 14.0 \\
GDM & 6 & 12.0 \\
Preterm Activity & 20 & 40.0 \\
Macrosomia & 9 & 18.0 \\
Total & $\mathbf{5 0}$ & $\mathbf{1 0 0 . 0}$ \\
\hline
\end{tabular}

IUGR: Intrauterine Growth Deficiency EMR: Early Membrane Rupture GDM: Gestational Diabetes Mellitus

Figure 1. ROC curve

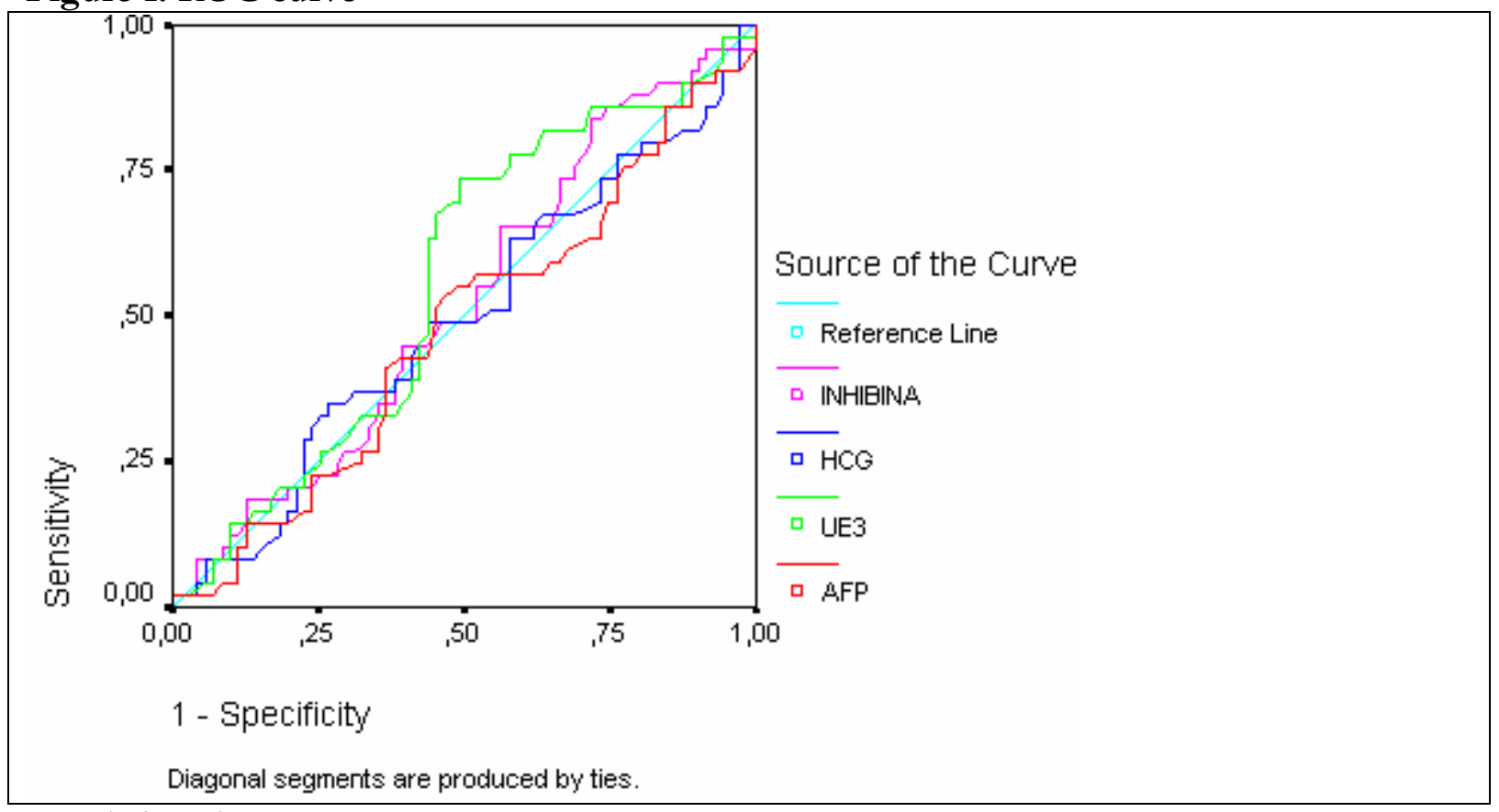

Area below the curve

AFP: Alfa-Fetoprotein HCG: Human Chorionic Gonadotropin, uE3: Unconjugated oestriol, ROC: Receiver Operating Characteric

Table 4. Relation between AFP, uE3, HCG and inhibin-A values and complication development in ROC analysis

\begin{tabular}{lcccccc}
\hline & Area & Std. Error & Asp. Sig. & $\begin{array}{l}\text { Asymptomatic } \\
\text { interval } \\
\text { Lower Limit }\end{array}$ & Upper Limit \\
\hline AFP & .476 & .054 & .650 & .370 & .581 \\
uE3 & .559 & .053 & .275 & .454 & .663 \\
hCG & .493 & .054 & .894 & .386 &, 599 \\
Inhibin A & .521 & .053 & .699 & .416 & .625 \\
\hline
\end{tabular}

AFP: Alfa-Fetoprotein, HCG: Human Chorionic Gonadotropin, uE3: Unconjugated oestriol 
Dinc, K., Ozyurt, R., S1k, A., Kumbasar, S., Akpak, Y. K., \& Aba, Y. A. (2017). Effects of secondary trimester maternal serum screening on the results of pregnancy. Journal of Human Sciences, 14(4), 3653-3662. doi:10.14687/jhs.v14i4.4806

No significant deviation between AFP, uE3, HCG and inhibin-A values and complication development found within the conducted ROC analysis. As AFP MoM threshold values considered as 1.5, 2.0 and 2.5, relation between complication observation frequency and AFP MoM values over threshold values found to be insignificant. $(\mathrm{p}=0.268 \mathrm{p}=0.224 \mathrm{p}=0.229$ respectively). As HCG MOM threshold values considered as 1.5 and 2.0, relation between complication observation frequency and HCG MOM values over these threshold values found to insignificant- $(\mathrm{p}=0.479, \mathrm{p}=0.872$ ). As threshold value for $\mathrm{uE} 3 \mathrm{MoM}$ considered as 0.8 relation between complication observation frequency and $\mathrm{uE} 3 \mathrm{MoM}$ values over these threshold values found to significant: $(p=0.001)$. In other words, as the threshold values of $\mathrm{uE} 3 \mathrm{MoM}$ values considered as $0.6,0.7,0.8$ and 0.9 a significant relation between complication observation frequency and $\mathrm{uE} 3 \mathrm{MoM}$ values over these threshold values were identified $(\mathrm{p}=0.129)$.

As threshold values of Inhibin-A MoM considered as 1.5 and 2.0, relation between complication observation frequency and HCG MoM values over these threshold values found to be insignificant ( $\mathrm{p}=0.87, \mathrm{p}=0.910$ respectively).

Out of 120 cases participated in the study for 70(\%58.3) non-complication cases average AFP value calculated as $1,00 \pm 0,74 \mathrm{MoM}, \mathrm{uE} 3$ value calculated as $0,89 \pm 0,4 \mathrm{MoM}$, hCG value calculated as $0,97 \pm 0,5 \mathrm{MoM}$ and average Inhibin A value calculated as $0,95 \pm 0,5 \mathrm{MoM}$. For 50 (\%41.6) cases developed complications, average AFP value calculated as $1,06 \pm 0,74$, uE3 value calculated as 0,96 $\pm 0,39 \mathrm{MoM}$, hCG value calculated as $0,99 \pm 0,77 \mathrm{MoM}$ and Inhibin-A value calculated as 1,023 $\pm 0,62 \mathrm{MoM}$. There is no significant deviation between complication and non-complication group in terms of AFP, uE3, HCG and Inhibin-A values ( $p>0,05)$ (Table 5).

Table 5. Comparison of complication and non-complication groups in terms of AFP, uE3, HCG and Inhibin A values

\begin{tabular}{lccccc} 
& \multicolumn{2}{c}{ Complication Unpresented } & Complication Present $(\mathbf{n}=\mathbf{5 0})$ & $\mathbf{p}$ \\
& $\mathbf{M}$ & $\mathbf{( n = 7 0 )}$ & $\mathbf{~} \mathbf{M}$ & $\mathbf{s d}$ & \\
\hline AFP & 1.0080 &, 7440 & 1,069 &, 7427 &, 615 \\
$\mathbf{u E 3}$ & .8955 &, 4089 &, 9668 &, 3900 &, 274 \\
hCG & .9734 &, 5482 &, 9942 &, 7717 &, 850 \\
Inhibin A & .9568 &, 5281 & 1,0235 &, 6251 &, 699 \\
\hline
\end{tabular}

AFP: Alfa-Fetoprotein, HCG: Human Chorionic Gonadotropin, uE3: Unconjugated oestriol M: Mean

\section{Discussion}

Purpose of the screening tests is to screen biggest population possible and diagnose the high risk pregnancies in terms of genetic diseases. For this purpose, ultrasonography and analysis methods of biochemical indicators in maternal blood are commonly used in present times. Thus there is no agreement over the prenatal screen tests, a lot of studies still conducted on this subject (Brock et al., 1999; Hamilton et. al. 1985). Conducted studies focused either on developing a new protocol or specificity and sensitivity in birth anomalies (Brock et al., 1999; Hamilton et. al. 1985). Threshold values of secondary trimester MSAFP, HCG, uE3 and Inhibin-A are reported in different studies.

First Brock et. al (1997) researched the presence of relation between maternal AFP level and low birth weight and reported 2.5 times more low birth weight for the cases where the AFP values are over 2.3 threshold value. Hamilton et. al. (1985) who considered AFP threshold value as $2.5 \mathrm{Mom}$, reported 10 times lower birth rate, 10 times more preterm activity risk, 3 times more 
Dinc, K., Ozyurt, R., S1k, A., Kumbasar, S., Akpak, Y. K., \& Aba, Y. A. (2017). Effects of secondary trimester maternal serum screening on the results of pregnancy. Journal of Human Sciences, 14(4), 3653-3662. doi:10.14687/jhs.v14i4.4806

ablatio placenta risk and 8 times more perinatal death risk for the cases with AFP levels over this threshold value. In our study AFP values are observed as $<=1.5 \mathrm{MoM}$ for $47(94.0 \%)$ for pregnancies with complication against $3(6.0 \%)$ pregnancies without complication with AFP values as $>1.5 \mathrm{MoM}$. If we consider AFP threshold values as 2 and $2.5 \mathrm{MoM}$, we observed $<49$ $(98.0 \%)$ and $1(2 \%)$ complicated pregnancies for the both two truncations. No statistically significant risk increase found. In our study, this kind of a risk increase were not identified however the reason behind this might be because of our study with low risk population. No significant increase in the risk observed in our study between normal and low birth weight for the whole AFP MoM threshold values in our study (1.5, 2.0 and 2.5). In most of the studies, 2 or 2.5 MoM levels used as truncation values for describing the higher AFP status. We did not find any high risk relation between AFP values and pregnancy complications as IUGR, Preterm ActivityBirth, GDM, EMR, and preeclampsia.

Relation between secondary trimester maternal serum HCG level and pregnancy complications drew attention of the many researchers. Abnormal increase in HCG levels might result in decrease of the placental perfusion by decreasing the oxygenation of cytotrophoblast. Lieppman et. al. (1993) used $2 \mathrm{MoM}$ as the threshold value and reported 2, 8 times increased rate of premature birth risk, 4 times increased low birth weight risk for the gravids over this threshold value. In our study, we identified $37(84.0 \%)$ complicated pregnancies with HCG threshold value of $\leq 1.5 \mathrm{MoM}$ against $13(16.0 \%)$ complicated pregnancies with HCG value of $>1.5 \mathrm{MoM}$. By considering HCG threshold value as $<2$ Mom, we identified $46(92.0 \%)$ complicated pregnancies and identified $4(8.0 \%)$ complicated pregnancies as we considered threshold value as $>2$ MoM. No statistically significant risk increase found. This kind of risk were not identified in our study. In most of the studies, 2 or $2.5 \mathrm{MoM}$ levels used as truncation values for describing the higher HCG status. We did not find any high risk related between HCG values and pregnancy complications as IUGR, Preterm Activity-Birth, GDM, EMR, and preeclampsia.

Two mechanisms asserted regarding higher HCG levels. First theory is "reactive hyperplasia of the cytotrophoblastic cells exposed to hypoxia". According to an another hypothesis, weight and volume of the placenta is greater in the cases where the HCG levels increased, and as a result it might be reflecting a healthier placental implantation with bigger babies (Sayin et. al., 2008). However, Mikic \& Johnson (1999), claimed that higher isolated maternal serum beta-hCG levels are not an indicator for other pregnancy complications and IUGG.

We did not find any statistically significant relationship between serum HCG levels and pregnancy results as similar to Mikic \& Johnson (1999). In our study, we identified $37(84.0 \%)$ complicated pregnancies with HCG threshold value of $\leq 1.5 \mathrm{MoM}$ against $13(16.0 \%)$ complicated pregnancies with HCG value of $>1.5 \mathrm{MoM}$. By considering HCG threshold value as $<2 \mathrm{MoM}$, we identified $46(92.0 \%)$ complicated pregnancies and identified $4(8.0 \%)$ complicated pregnancies as we considered threshold value as $>2$ MoM. No statistically significant risk increase found. No comparison between these groups conducted as a result of having low number of patients with AFP and HCG values of 2.5 MOM. Our study needs to be supported by increasing the number of patients and conducting prospective studies.

Smith et. al. (2007). compared the PAPP-A and $\beta$-hCG values with pregnancy results in 8839 gravids which were in their 8th and 14th weeks, and stated that gravids with PAPP-A values lower than $5 \%$ are exposed to IUGR, premature birth, preeclampsia and stillbirth risks while for the gravids with free $\beta$-hCG values below 5 percentile are exposed to IUGR risk. Huang et. al. (2010) in their retrospective compositions including 141698 gravids, relation between biochemical indicators obtained during first and secondary trimester and Down Syndrome screening and pregnancy results and as compared with the control group AFP and total hCG levels found to be significantly higher in terms of preeclampsia, IUGR and fetal loss while PAPP$A$ and oestriol levels found to be significantly lower. In an another retrospective cohort study 
Dinc, K., Ozyurt, R., S1k, A., Kumbasar, S., Akpak, Y. K., \& Aba, Y. A. (2017). Effects of secondary trimester maternal serum screening on the results of pregnancy. Journal of Human Sciences, 14(4), 3653-3662. doi:10.14687/jhs.v14i4.4806

conducted with 2844 cases multiple of Median (MoM) value for $\beta$-hCG and PAPP-A found to be lower compared to control group in terms of preeclampsia, premature birth, IUGR and decollement placenta cases (Ranta et. al., 2011). In some studies for the PAPP-A MoM value inspected between 11th and 13th pregnancy week, thus reported to be lower compared to control cases in terms of preeclampsia (Carbone et. al., 2011; Poon et. al., 2010), in some cases no differences between the groups were found (Mikat et. al., 2012; Vandenberghe et. al., 2011), and screening performance of serum PAPP-A for early start preeclampsia and IUGR reported as week (Vandenberghe et. al., 2011).

In addition to AFP and hCG results, there are limited number of studies conducted on researching the relation between $\mathrm{uE} 3$ levels and pregnancy complications. Pergament et. al. (1995) considered the threshold value as 0.75 for trimester screening and pregnancy complication values and found the occurrence of intrauterine growth deficiency to be more frequent for the gravids whom have MoM levels below the threshold value. Kowalczyk et. al. (1998) reported that the occurrence of intrauterine growth deficiency and oligohydramniosis to be significantly more frequent for the gravids with uE3 levels below 0.75 MoM threshold value. Ben et. al. (1996), reported that more number of bad pregnancy results observed in the cases with higher secondary trimester AFP and HCG levels. In a similar study like ours which were conducted in Turkey, no relation between lower indirect oestriol levels with preterm activity, IUGR, macrosomia, fetal distress found only, but a relation with GDM were found for $\mathrm{uE} 3 \leq 0.5 \mathrm{MoM}$. In our study, we identified $3(6.0 \%)$ complicated pregnancies with uE3 threshold value of $\leq 0.6 \mathrm{MoM}$ against 47 (94.0\%) complicated pregnancies with hCG value of $>0.6 \mathrm{MoM}$. We did not identified a statistically significant increase in preterm activity, IUGR, macrosomia and EMR.

Inhibin-A is known as the only roaming mature inhibin type during pregnancy. In the published articles Tul et. al. (2003) reported a significant relationship between higher Inhibin-a levels and preterm birth. Diagnosis of preeclampsia were left for the weeks between 20 and 22 as the preeclampsia symptoms usually develop during late secondary trimester and 3rd trimester. , In an another study, a relation between the high levels of Inhibin-A in mother's serum in secondary trimester and preeclampsia and IUGR (D'Anna et. al., 2002). Lambert-Messerlian et al (2000) stated that, for the cases in secondary trimester with higher Inhibin-A and hCG levels developed a high rate of late start preeclampsia while stating Inhibin-A's superiority for identifying early start preeclampsia. In our study we identified $44(89.2 \%)$ complicated cases with Inhibin-A MoM values $<2$ and $6(10.2 \%)$ cases with Inhibin-A MoM values with $>6$ while there is not a significant relationship if threshold value for Inhibin-A MoM considered as 2.0. $(p=0.910)$. In our study, we did not find high risk related with inhibin a for the pregnancy complications as IUGR, preterm activity-birth, GDM, EMR and preeclampsia.

Spencer et al. (2006) conducted a case control study comprised of 24 cases with developed preeclampsia and 144 normotensive cases. PAPP-A, free $\beta$-HCG activine A, inhibin A levels were inspected in the cases between 22 nd and 25 th pregnancy weeks, a significant increase found for group which developed preeclampsia compared to control group in terms of serum PAPP-A, free $\beta$-hCG, activine A and activine B levels. Lower levels of PAPP-A $(<0.4 \mathrm{MoM})$ and hCG $(<0.5 \mathrm{MoM})$ levels in first trimester, higher levels of AFP $(>2.5 \mathrm{MoM})$, HCG $(>3$ $\mathrm{MoM})$, inhibin $\mathrm{A}(\geq 2 \mathrm{MoM})$ and lower levels of AFP $(<0.25 \mathrm{MoM}), \mathrm{E} 3(<0.5 \mathrm{MoM})$ in secondary trimester are reported to be in relation with increased pregnancy complications, but at the same time it was reported that these indicators have lower sensitivity for identifying obstetric complications and having high rate of false positive identifications; and if high levels of AFP is present in secondary or third trimester with placenta praevia, placenta acreata, increata, percreata should be suspected (Gagnon et. al., 2008).

Dugoff et. al. (2005) for the 33145 cases where AFP, hCG, E3 and Inhibin A inspected; reported increased pregnancy complications where one of the values are abnormal while reported increased pregnancy complications with increased significance in the presence of more than one 
Dinc, K., Ozyurt, R., S1k, A., Kumbasar, S., Akpak, Y. K., \& Aba, Y. A. (2017). Effects of secondary trimester maternal serum screening on the results of pregnancy. Journal of Human Sciences, 14(4), 3653-3662. doi:10.14687/jhs.v14i4.4806

abnormal parameters. However, the sensitivity of these parameters for identifying the pregnancy complications is low.

\section{Conclusion}

No significant relation between threshold values of AFP, hCG, uE3 and inhibin A which are used in quad test as secondary trimester serum indicators in low risk populations and pregnancy complications. In order the decrease bad fetomaternal results, more prospective studies including bigger populations with greater number of patients required to be conducted regarding increasing the fetal survival.

\section{References}

Bobyr, R., Vile, Y. (2005). First Trimester Screening Tests. In: James DK, Steer PJ, Weiner CP, Gonic B, editors. High Risk Pregnancy Textbook. 3rd edition. London; Sounders Elservier. 150-157.

James, DK., Steer, PJ., Weiner, CP., Gonik, B. (2008). Yüksek Riskli Gebelikler Yönetim Seçenekleri. Erken prenatal bakım (Derleyen: Güner H), Güneş Tıp Kitabevleri, İstanbul. 65.

Kafkasli, A. (2004). Screening Tests and Reliability for Down Syndrome Diagnosis in Pregnancy. Turkish Gynecology and Obstetrics Association Post-Specialist Education Journal. 6: 30-35.

Smith, GC., Stenhouse, E., Crossley, JA., Aitken, DA., Cameron, AD., Connor, JM. (2002). Early pregnancy levels of pregnancy-associated plasma protein a and the risk of intrauterine growth restriction, premature birth, preeclampsia, and stillbirth. J Clin Endocrinol Metab. 87: 1762-7.

Chandra, S., Scott, H., Dodds, L., Watts, C., Blight, C., Van Den Hof, M. (2003). Unexplained elevated maternal serum alpha-fetoprotein and/or human chorionic gonadotropin and the risk of adverse outcomes. Am J Obstet Gynecol. 189: 775-81.

Lindheimer, MD., Roberts, JM., Gary, F. (2009). Hypertensive disorders in pregnancy. In: Chesley's ed. 3rd ed. San Diego: Elseiver, 222.

Wallace, EM., Crossley, JA., Groome, NP., Aitken, DA. (1997). Amniotic fluid inhibin-A in chromossomally normal and Down's syndrome pregnancies. J Endocrinol . 152: 109-12.

Knoshnood, B., Greenlees, R., Loane, M., Dolk H. (2011). EUROCAT Project Management Committee; EUROCAT Working Group. Paper 2: EUROCAT public health indicators for congenital anomalies in Europe. Birth Defects Res A Clin Mol Teratol. 91(Suppl 1): 16-22.

Krantz, DA., Hallahan, TW., Sherwin, JE. (2010). Screening for open neural tube defects. Clin Lab Med. 30: 721-5.

Cameron, M. \& Moran, P. (2009). Prenatal screening and diagnosis of neural tube defects. Prenat Diagn. 29: 402-11.

Brock, DJ., Baron, L., Jelen, P., Watt, M., Scrimgeour, JB. (1997). Maternal serum alpha-fetoprotein measurementsas an early indicator of low birth weight. Lancet. 2: 267-268.

Hamilton, MP., Abdalla, HI., Whitfield, CR. (1985). Significance of raised maternal serum alphafetoprotein in singleton pregnancies with normally formed fetuses. Obstet Gynecol. 65: 465-470.

Lieppman, RE., Williams, MA., Cheng, EY., Resta, R., Zingheim, R., Hickok, DE., Luthy, DA. (1993). An association between elevated levels of human chorionis gonadotropin in the midtrimester and adverse pregnancy outcome. Am J Obstet Gynecol. 168: 1852-1857

Sayin, N., Canda, M., Ahmet, N., Varol, FG. (2008). The association of triple-marker test results with adverse pregnancy outcomes in low-risk pregnancies with healthy newborns. Arch Gynecol Obstet. 277: 47-53.

Mikic, TS. \& Johnson, P. (1999). Second trimester maternal $\beta$ human chorionic gonadotrophin and pregnancy outcome. BJOG. 106: 598-600.

Smith, GC., Shah, I., White, IR., Pell, JP., Crossley, JA., Dobbie, R. (2007). Maternal and biochemical predictors of antepartum stillbirth among nulliparous women in relation to gestational age of fetal death. BJOG. 114: 705-14. 
Dinc, K., Ozyurt, R., S1k, A., Kumbasar, S., Akpak, Y. K., \& Aba, Y. A. (2017). Effects of secondary trimester maternal serum screening on the results of pregnancy. Journal of Human Sciences, 14(4), 3653-3662. doi:10.14687/jhs.v14i4.4806

Huang, T., Hoffman, B., Meschino, W., Kingdom, J., Okun, N. (2010). Prediction of adverse pregnancy outcomes by combinations of first and second trimester biochemistry markers used in the routine prenatal screening of Down syndrome. Prenat Diagn. 30: 471-7.

Ranta, JK., Raatikainen, K., Romppanen, J., Pulkki, K., Heinonen, S. (2011). Decreased PAPP-A is associated with preeclampsia, premature delivery and small for gestational age infants but not with placental abruption. Eur J Obstet Gynecol Reprod Biol. 157: 48-52.

Carbone, IF., Cruz, JJ., Sarquis, R., Akolekar, R., Nicolaides, KH. (2011). Assisted conception and placental perfusion assessed by uterine artery Doppler at 11-13 weeks' gestation. Hum Reprod. 26: 1659-64.

Poon, LC., Stratieva, V., Piras, S., Piri, S., Nicolaides, KH. (2010). Hypertensive disorders in pregnancy: combined screening by uterine artery Doppler, blood pressure and serum PAPPA at 11-13 weeks. Prenat Diagn. 30: 216-23.

Mikat, B., Zeller, A., Scherag, A., Drommelschmidt, K., Kimmig, R., Schmidt, M. (2012). ßhCG and PAPP-A in first trimester: Predictive factors for preeclampsia? Hypertens Pregnancy. 32: 261-7.

Vandenberghe, G., Mensink, I., Twisk, JW., Blankenstein, MA., Heijboer, AC., Van Vugt, JM. (2011). First trimester screening for intra-uterine growth restriction and early-onset pre-eclampsia. Prenat Diagn. 31: 955-61.

Pergament, E., Stein, AK., Cho, NH., Kupfermine, MJ. (1995). Adverse pregnancy outcome after a false positive screen for Down Syndrome using multiple markers. Obstet Gynecol. 86: 255-258.

Kowalczyk, TD., Cabaniss, ML., Cusmano, L. (1998). Association of low unconjugated estriol in the second trimester and adverse pregnancy outcome. Obstet Gynecol. 91: 396-400.

Benn, PA., Horne, D., Briganti, S., Rodis, JF., Clive, JM. (1996). Elevated second-trimester maternal serum hCG alone or in combination with elevated alpha-fetoprotein. Obstet Gynecol. 87: 21722.

Tul, N., Pusenjak, S., Osredkar, J., Spencer, K., Novak-Antolic, Z. (2003). Predicting complications of pregnancy with first-trimester maternal serum free-beta hCG, PAPP-A and inhibin-A. Prenat Diagn. 23: 990-996.

D'Anna, R., Baviera, G., Corrado, F., Leonardi, I., Buemi, M., Jasonni, VM. (2002). Is mid-trimester maternal serum inhibin-A a marker of preeclampsia or intrauterine growth restriction? Acta Obstet Gynecol Scand. 81: 540-3.

Lambert-Messerlian, GM., Silver, HM., Petraglia, F., Luisi, S., Pezzani, I., Maybruck, WM. (2000). Second-trimester levels of maternal serum human chorionic gonadotropin and inhibin a as predictors of preeclampsia in the third trimester of pregnancy. J Soc Gynecol Investig. 7: 170-4.

Spencer, K., Yu, CK., Savvidou, M., Papageorghiou, AT., Nicolaides, KH. (2006). Prediction of preeclampsia by uterine artery Doppler ultrasonography and maternal serum pregnancy associated plasma protein- $\mathrm{A}$, free beta-human chorionic gonadotropin, activin $\mathrm{A}$ and inhibin A at $22+0$ to $24+6$ weeks' gestation. Ultrasound Obstet Gynecol. 27: 658-63.

Gagnon, A., Wilson, RD., Audibert, F., Allen, VM., Blight, C., Brock, JA. (2008). Obstetrical complications associated with abnormal maternal serum markers analytes. $J$ Obstet Gynaecol Can. 30: 918-49.

Dugoff, L., Hobbins, JC., Malone, FD., Vidaver, J., Sullivan, L., Canick, JA. (2005). Quad screen as a predictor of adverse pregnancy outcome. Obstet Gynecol. 106: 260-7. 